\title{
Design of Mobile Application for Community Health Workers: A Case Study in Rwanda
}

\author{
https://doi.org/10.3991/ijim.v14i11.13307
}

\author{
Gahizi Emmanuel, Andi W.R. Emanuel ${ }^{(凶)}$, Djoko Budiyanto Setyohadi \\ Universitas Atma Jaya Yogyakarta, Yogyakarta, Indonesia \\ andi.emanuel@uajy.ac.id
}

\begin{abstract}
Community health workers (CHWs) are the basis of public health services that aim to connect the gap between public health and the human service system. This gap can be bridged entirely by navigating the health aspects of human service systems and educating communities on disease prevention. Unfortunately, the way of sharing, accessing information, and delivering health services is still non-digitalized in Rwanda. Community Health workers use a manual system in their daily activities, which is prone to error and falsification. Moreover, these people selected to perform these activities often do not have adequate knowledge about diseases and health systems since they are not professional health workers. To address the above problem, we designed a prototype mobile application to enable these workers to automatically submit reports, transfer knowledge, share information, and receive training from professionals. The design process followed a User-Centered Design approach to meet the users' requirements. The evaluation of the design showed that $91.7 \%$ of the CHWs agreed with the designed application prototype. This finding indicates that $\mathrm{CHW}$ s has an interest in using the mobile application in their work. Using the mobile application will help CHWs to improve data collection, the reporting process, and ease of receiving training.
\end{abstract}

Keywords - Health Systems, mobile application, community health workers, User-Centered Design.

\section{Introduction}

Over the last decade, mobile applications based on Community Health Workers (CHWs) activities have played a significant role in communities to promote community health. About $95 \%$ of the aggregate masses right now are presently connected with a flexible mobile network[1]. The number of mobile users is expected to pass 4.8 billion, with over 67 percent mobile phone penetration in 2019. As a consequence, Mobile Health is encountering a developmental incline as clients request a great deal of access to their medicinal wellbeing experts. A good percentage of aid customers believe that mobile application services can reduce a person's own health care costs [2][3].

Rwanda's CHWs are still facing difficulties in their daily health works. They collect data and make reports by filling hard copies given to them by health professionals. This 
method is not trustworthy as it is prone to mistakes, and sometimes the hard copies can get lost or get damaged. Workers also encounter high expenses by making phone calls since there is no easy way of accessing and sharing information. Above all, they don't have an automated system to be used by health professionals such as data managers, supervisors, and doctors. To overcome all the above challenges, we designed a mobile application using the User-Centered Design method to address the above problems. This application is expected to be effective communication media between health care professionals and community health workers. The application is designed based on five stages, namely; identifying user needs, specifying the context of use, specifying requirements, producing design solutions, and evaluating design. Hopefully, sharing and reporting of information for Rwanda CHWs will have a new automated method that suits several difficulties and will make increased confidentiality.

\section{$2 \quad$ Literature Review}

\subsection{Mobile users detail illustration in Rwanda}

Rwanda, located in the East of Africa, is predicted to adopt a $4 \mathrm{G}$ network and drop the use of $2 \mathrm{G}$ by the year 2023 . The use of $4 \mathrm{G}$ will rise to $23 \%$ of connections by 2025[4]. Rwanda has a mobile penetration of $29.8 \%$ of the population, according to Rwanda Utilities Regulation Administrative (RURA) [5]. This amplified accessibility of mobile devices that has an intersection rectifier to the occasion of the circle of versatile wellbeing (mHealth).

\subsection{Community health workers}

In Rwanda, the CHW program was started in 1995 after the 1994's Tusti Genocide to strengthen the coordination of community health services since the number of professional medical workers was not enough. $\mathrm{CHWs}$ play the role of reporting problems caused by the difficulty of accessing the base health care[6]. In Low Middle-Income Countries (LMICs), CHWs help in family-based prenatal and postpartum care directions [7]. WHO estimates that there are is a lack of 7.2 million Healthcare laborers, and this crisis will reach 12.9 million by 2035[8]. General CHWs are grouped into several categories, such as community health professionals, volunteer medical examiners, community health educators, and Frontline Health Workers (FHWs) [9].

According to global health, CHWs play an enormous role in the standard of living in middle-income countries[10]. They measure the key to accomplishing the development of the health's Sustainable Development Goals by enrolling essential health services toward Universal Health Coverage (UHC) [11]. 


\subsection{Solutions to challenges faced by CHWS}

The challenges faced by CHWs can be handled by putting into consideration the use of technologies, financial support, and strong organizational structure. The CHWs programs should include training for supervisors and other health staff to ensure appropriate support. The support must concentrate mainly on the projects that utilize innovative help [12]. The health system should not keep behind since new versatile data innovations increasingly being produced, tried, and steered with CHWs. The utilization of automation by $\mathrm{CHW}$ can enhance medicinal service administrations with instinctive attraction [13].

\subsection{The advantage of using the mobile health system}

mHealth is defined as medical service delivery with the help of mobile phones and other associated remote gadgets. mHealth empowers CHWs to give wellbeing administrations a long way from the clinical setting and has many frames like operator interaction and feedback [14]. The use of mobile technology makes a trusted method of data gathering by using a mobile phone to send data and receive check out a request by CHWs [15]. The mobile phone is chosen because it improves outcomes for CHWs in their daily activities. It also enhances the value of responsibility, provides coherence and capacity of program monitoring[16]. The studies incorporated in this research allow the accumulation of patient information, encourages leaders to make decisions towards patient status according to their data and also preparing for a future crisis by giving alerts and updates[17].

\subsection{Related research}

We have respectively returned to the initial existing research for application and collection of data, resulting in good research results. It was necessary to know what is found in other studies on the same field on the use of mobile technologies. Both theoretical and technical methods were reviewed to contributed to this study. Therefore, in Table 1, concerning the study, their goals are listed as follows:

Table 1. Research and objectives related to this research

\begin{tabular}{|l|l|}
\hline \multicolumn{1}{|c|}{ Research } & \multicolumn{1}{c|}{ The aim of the study } \\
\hline Orawit et al.[18] & $\begin{array}{l}\text { To develop a pharmacy assistant mobile application for primary med- } \\
\text { ication }\end{array}$ \\
\hline Ferreira et al.[19] & To collect data and to help CHWs to achieve their goal \\
\hline Angula.N et al. [20] & $\begin{array}{l}\text { To examine how information relating to healthcare can be distributed } \\
\text { and accessed through mobile technologies }\end{array}$ \\
\hline Orawit et al.[21] & To support users in the initial medication \\
\hline Stathopoulou, A. et al. [22] & To assess the use of the mobile application for health services \\
\hline Dahri et al. [23] & $\begin{array}{l}\text { To Investigate the usability of evaluation of the Mobile Health appli- } \\
\text { cation by patients' task performance evaluation and satisfaction. }\end{array}$ \\
\hline
\end{tabular}


The mobile application has excellent advantages for data collection in different fields of activities. As shown in Table 1, the use of mobile applications motivates CHWs in their daily activities. Mobile application usability has useful features that users can learn and use [23]. Furthermore, Stathopoulos et al. state that mobile devices are the best technology for accessing knowledge as they are quite attainable and accessible to use mainly by those who have learning difficulties[22]. This research aims at designing a mobile application that will help to collect, report, share, and access information related to health care service delivery for Rwandan society. After reviewing the related research presented in table 1 , we get more insight into what should be considered for designing the application.

\section{$3 \quad$ Research Methodology}

\subsection{Data collection methods}

In this research, we used data from secondary sources such as related research done related to CHWs and Mobile application design, WHO report, and Rwanda Ministry of Health $(\mathrm{MoH})$ report. Primary data sources are gathered using questionnaires in Google form. The primary data also included socio-demographic information such as age, sex, education level. The survey composed of 20 items, and assessed the reliability and validity based on the five-point Likert scale from Strong disagree=1, Disagree=2, Less agree $=3$, Agree $=4$, and Strong agree $=5$. Details regarding the question were articulated adequately to the respondents before filling the questionnaire.

\subsection{Participant and sample size of the study}

The participants of the study were 210 participants with a population size of 137 participants are CHWs from Ngarama hospital. Ngarama Health center was chosen because it is covering both urban and City regions. In determining the sample size, a table for determining the number of samples from a particular population was developed from Isaak and Michael [24], for an error rate of 5\% so that it can obtain 95\% confidence.

\section{Data Analysis and Application Design and Analysis}

The Cronbach's alpha, Pearson Correlation (r.p.n) was used to analyze various characteristics of the sample population, such as gender, age, education level. The results of the questionnaire were used to test the reliability and validity of mobile application design. In the design of a mobile application for CHWs, Adobe XD desktop application, Adobe creative cloud, and adobe XD Mobile application because they are open-source software, and make it easy to test the designed prototype over the android mobile phone. 


\title{
4.1 Application design
}

The application prototype has several icons; each icon represents the task to be completed by both stakeholders of the application stated above.

\section{Welcome}

\author{
to Rwanda CHWs mobile application
}

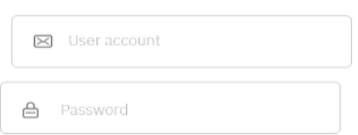

CREATE ACCOUNT

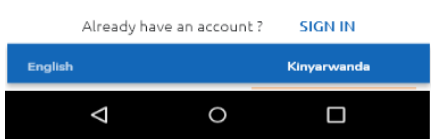

Fig. 1. Login page

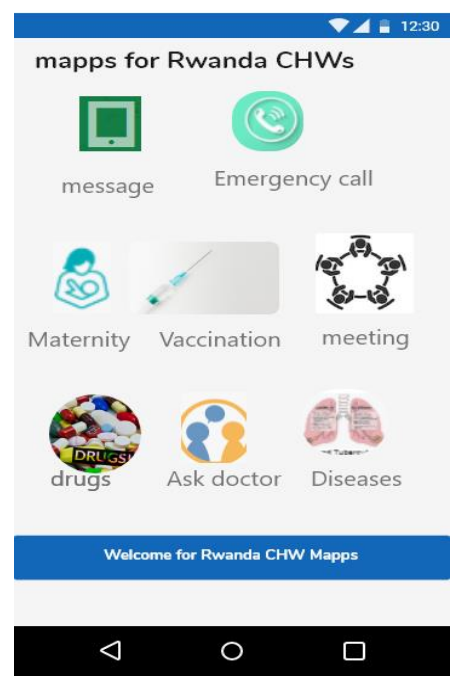

Fig. 2. Home page

Figure 1 and figure 2 are the main pages of an application prototype. Figure 1 enables the accessibility of the application, and it allows the user to login. As in Figure 1, the form checks if the user valid and password, then he /she will proceed to the home page. Figure 2 is the main page of an application. Where it has sub icon such as message 
which allow information sharing through text, maternity, vaccination, drugs, meeting, diseases, emergency call and ask the doctor. The CHWs will be able to interact with both the presented icon within the application in their daily activities. They will be able to collect and report maternity, vaccination, diseases, and meeting information; furthermore, they will be able to consult the doctor for advanced help when it is an emergency.

\subsection{Reliability and validity test}

Based on the results of the reliability test has the Cronbach's alpha results of 0.963 , which exceeded the standard limit of 0.7 , so the questionnaires are reliable[26]. The question is declared valid because the total value of each item exceeds the standard value. Test results show all question scores are higher than 0.3610 . The questions are declared valid because the total value of each question exceeds the standard value. Moreover, test results show all question scores are higher than 0.7.

\subsection{Evaluation of the results}

After collecting and analyzing data, we found that the mobile application for CHWs has the potential effect for both CHWs and Health system Mangers in Rwanda. As the result shows, we assure that if the government put into consideration, the mobile application for CHWs will bring many benefits for health care services.

The social demographics data shows that the number of women is higher compared with men; also, there is a higher number of participants with age over 36 years old, which is $79 \%$. The educational background shows that $74.5 \%$ of CHWs only have a primary level of education.

The overall results from questionnaire for 4 and 5 categories was $91.7 \%$. It shows that the CHWs understand and agree with the design of the mobile application.

\section{Discussion, Limitation, and Conclusion}

\subsection{Discussion}

The part of the result evaluation tended to evaluate the problems faced by Rwanda Community Health workers caused by using the non-digitalized system for sharing, accessing, and delivering health services. Therefore, the difficulties faced by CHWs can be overcome by taking into account the use of technology, financial support, and strong organizational structure. The program of CHWs must involve training for coordinators and other health staff to provide adequate support to promote health services.

The present study has also found out that most of the developing countries, including Rwanda, still use paper-based methods in collecting and reporting health data. Rwanda's two existing systems, namely Siscom and Rwanda Integrated Health management Information System are used only by the high-level health staff (Data managers, District, Health Officer) who are policymakers and decision-makers. 
Based on data collected, we have seen that the majority of Rwanda CHWs are female presented by $78.1 \%$ while the rest are male. This result shows that the female is engaged more than male, even though the Rwandan government promotes the balance of gender. These gaps exist because men buffer the stress caused by economic responsibilities, family, and personal problems. The results show that Rwandan youths are not participating in community health services as the estimated percentage of $79 \%$ of CHWs presents the people aged above 36 years old. This condition is because of educational reasons since the Rwandan government calls its youth to attend the school first. The balance between each division admits that the CHWs program still has challenges to be solved. There are different types of health data collected, such as sick child care, supervision, and participation of maternal health, and disease follow-up information to improve health services in Rwanda.

\subsection{Limitation of the proposed design}

The application design prototype was tested on Android-based mobile phones, and the current prototype has been verified to work on Google Cloud only.

\section{Conclusion}

A prototype of the mobile application for Rwandan Communities Health workers has been designed to enable CHWs to submit reports automatically, transfer knowledge, share information, and receive training from professionals. The challenging features and functionalities of the prototype application were designed, evaluated, and tested on Android phones using adobe XD cloud. As a result, $91 \%$ of the respondents agreed with the developed prototype. The results show users' acceptance level and their attitude of desiring the application to continue to the next phase of implementation. The mobile application designed will create durable, imperishable answers for tending to the Rwandan CHWs' healthcare needs.

Future studies in this research area could attempt to design a mobile application that uses the data from the primary sources (CHWs). The next focus could be on policymakers to enhance health data visualization, improve the analysis process by adding an interface page, explore ways to prevent the fragmentation of information, and enhance ICT's privacy and security of health data.

\section{$7 \quad$ References}

[1] S. Lee, Y. min Cho, and S. Y. Kim, "Mapping mHealth (mobile health) and mobile penetrations in sub-Saharan Africa for strategic regional collaboration in mHealth scale-up: An application of exploratory spatial data analysis," Global. Health, vol. 13, no. 1, pp. 1-11, 2017. https://doi.org/10.1186/s12992-017-0286-9

[2] O. Ilozumba, S. Van Belle, M. Dieleman, L. Liem, M. Choudhury, and J. E. W. Broerse, "The Effect of a Community Health Worker Utilized Mobile Health Application on Maternal 
Health Knowledge and Behavior: A Quasi-Experimental Study," Front. Public Heal., vol. 6, no. May, pp. 1-10, 2018. https://doi.org/10.3389/fpubh.2018.00133

[3] M. Oliver, A. Geniets, N. Winters, I. Rega, and S. M. Mbae, "What do com-munity health workers have to say about their work, and how can this inform im-proved programme design? A case study with CHWs within Kenya," Glob. Health Action, vol. 8, no. 1, pp. 1-17, 2015. https://doi.org/10.3402/gha.v8.27168

[4] GSMA, "The Mobile Economy. Sub-Saharan Africa," GSMA Intell., pp. 1-35, 2019.

[5] WSIS, "REPUBLIC OF RWANDA DRAFT ( 1 st Physical Meeting ) WSIS + 10 : OVERALL REVIEW OF THE IMPLEMENTATION OF THE WSIS OUTCOMES," Kigali, 2015.

[6] M. A. Lopez, "Community health worker interventions," SpringerBriefs Pub-lic Heal., pp. 25-29, 2018.

[7] R. Dev, P. Kohler, M. Feder, J. A. Unger, N. F. Woods, and A. L. Drake, "A systematic review and meta-analysis of postpartum contraceptive use among women in low- And middle-income countries," Reprod. Health, vol. 16, no. 1, pp. 1-17, 2019. https://doi.org/ 10.1186/s12978-019-0824-4

[8] J. Campbell et al., "A universal truth: No health without a workforce," Gene-va, Switzerland, 2013.

[9] G. Emmanuel, G. G. Hungilo, and A. W. Rahardjo Emanuel, "A mobile ap-plication system for community health workers - A review," ACM Int. Conf. Pro-ceeding Ser., no. April, pp. 106-110, 2019.

[10] WHO, WHO guideline on health policy and system support to optimize community health worker programmes. Geneva, Switzerland: World Health Or-ganization, 2018.

[11] WHO, "Universal health coverage ( UHC )," Geneva, Switzerland, 2019.

[12] J. Haver, W. Brieger, J. Zoungrana, N. Ansari, and J. Kagoma, "Experiences engaging community health workers to provide maternal and newborn health ser-vices: Implementation of four programs," Int. J. Gynecol. Obstet., vol. 130, no. S2, pp. S32-S39, 2015. https://doi.org/10.1016/j.ijgo.2015.03.006

[13] K. Källander et al., "Mobile health (mhealth) approaches and lessons for in-creased performance and retention of community health workers in lowand mid-dle-income countries: A review," J. Med. Internet Res., vol. 15, no. 1, 2013. https://doi.org/10.2196/jmir.2130

[14] R. Walker, "Walking beyond our borders with frontline health workers in guatemala," Nurs. Womens. Health, vol. 17, no. 6, pp. 533-538, 2013. https://doi.org/10.1111/1751486x.12082

[15] R. N. M. Mpembeni et al., "Motivation and satisfaction among community health workers in Morogoro Region, Tanzania: Nuanced needs and varied ambi-tions," Hum. Resour. Health, vol. 13, no. 1, pp. 1-10, 2015. https://doi.org/10.1186/s12960-015-0035-1

[16] M. S. Rahaman, N. R. Oyshee, S. A. Pratik, and K. A. Al Mamun, "Develop-ing an mhealth application to empower community health service for married couple: Challenges and opportunities," 4th Int. Conf. Electr. Eng. Inf. Commun. Technol. iCEEiCT 2018, pp. 227233, 2019. https://doi.org/10.1109/ceeict.2018.8628143

[17] S. Agarwal, H. B. Perry, L. A. Long, and A. B. Labrique, "Evidence on feasi-bility and effective use of mHealth strategies by frontline health workers in devel-oping countries: Systematic review," Trop. Med. Int. Heal., vol. 20, no. 8, pp. 1003-1014, 2015. https://doi.org/10.1111/tmi.12525

[18] O. Thinnukool, P. Khuwuthyakorn, and P. Wientong, "Pharmacy Assistant Mobile Application (PAMA): Development and reviews," Int. J. Interact. Mob. Technol., vol. 11, no. 3, pp. 178-194, 2017. https://doi.org/10.3991/ijim.v11i3.6757 
[19] L. Ferreira Paz, V. Maran, A. Machado, and I. Augustin, "MECA: Mobile System Support for Brazilian Community Health Agents Program Based on Con-text-Awareness," IEEE Lat. Am. Trans., vol. 15, no. 8, pp. 1547-1555, 2017. https://doi.org/10.1109/tla.2017. 7994805

[20] N. Angula and N. Dlodlo, "Mobile technology for health information dissem-ination," 2017 IST-Africa Week Conf. IST-Africa 2017, pp. 1-8, 2017. https://doi.org/10.23919/ istafrica.2017.8102329

[21] O. Thinnukool, P. Khuwuthyakorn, P. Wientong, and T. Panityakul, "Non-prescription medicine mobile healthcare application: Smartphone-based software design and development review," Int. J. Interact. Mob. Technol., vol. 11, no. 5, pp. 130-146, 2017. https://doi. org/10.3991/ijim.v11i5.7123

[22] A. Stathopoulou et al., "Mobile assessment procedures for mental health and literacy skills in education," Int. J. Interact. Mob. Technol., vol. 12, no. 3, pp. 21-37, 2018.

[23] A. S. Dahri, A. Al-athwari, and A. Hussain, "Usability Evaluation of Mobile Health Application from AI Perspective in Rural Areas of Pakistan," Int. J. Inter-act. Mob. Technol., vol. 13, no. 11, pp. 213-225, 2019. https://doi.org/10.3991/ijim.v13i11.11513

[24] J. S. Oliver, "Metode Penelitian Kuantitatif Kualitatif DAN R\&D (cetakan," J. Chem. Inf. Model., vol. 53, no. 9, pp. 1689-1699, 2013.

[25] A. Hazra, "Using the confidence interval confidently," J. Thorac. Dis., vol. 9, no. 10, pp. 4125-4130, 2017.

[26] H. Rafique, F. Anwer, A. Shamim, B. Minaei-Bidgoli, M. A. Qureshi, and S. Shamshirband, "Factors affecting acceptance of mobile library applications: Structural equation model," Libri, vol. 68, no. 2, pp. 99-112, 2018. https://doi.org/10.1515/libri-2017-0041

\section{Authors}

Gahizi Emmanuel is currently pursuing a Master's of Informatics at University Atma Jaya Yogyakarta. His research interest is a mobile application, mobile computing and IoT. Email: thegammy2008@gmail.com

Andi W.R. Emanuel is a Full-time Lecturer at Universitas Atma Jaya Yogyakarta. His research interests in Software Engineering, Open Source Software, Open Source Communities, Software Metrics, and Software Quality. Email: andi.emanuel@uajy.ac.id

Djoko Budiyanto Setyohadi is a Professor in Informatics at Universitas Atma Jaya Yogyakarta. His research interests are Data Engineering, Information system management, and Human-computer interaction. Email: djoko.budiyanto@uajy.ac.id

Article submitted 2020-01-22. Resubmitted 2020-03-23. Final acceptance 2020-03-29. Final version published as submitted by the authors. 